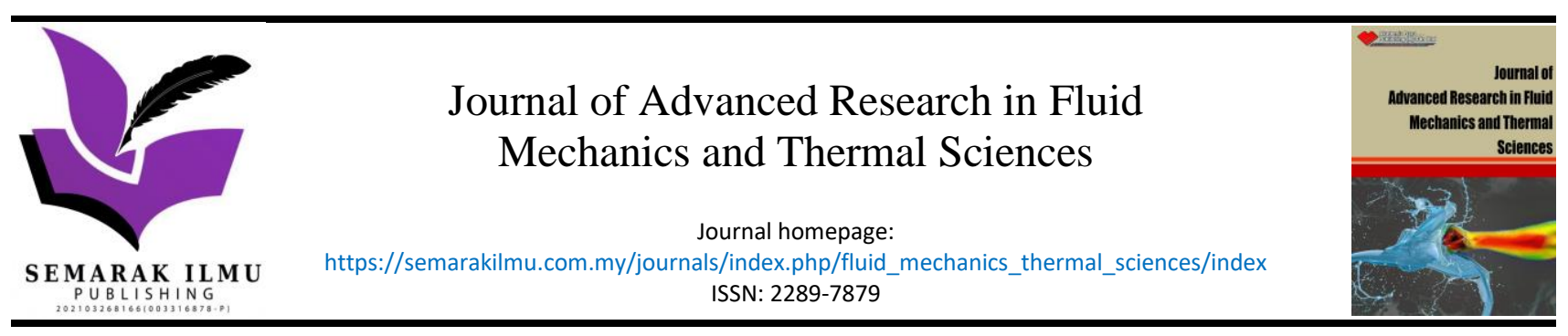

\title{
Thermal Characterization of Biofluids for Heat Transfer Fluid in Thermal Transport Technologies
}

\author{
Lukmon Owolabi Afolabi ${ }^{1,}{ }^{*}$, Oluwafunke T Afolabi-Owolabi ${ }^{2}$, Abdulhafid M Elfaghi ${ }^{1}$, Djamal Hissein \\ Didane ${ }^{1}$, Mohammed Ghaleb Awadh ${ }^{1}$, Al-Mahmodi Akram ${ }^{1}$ \\ Center for Energy \& Industrial Environment Studies (CEIES), Faculty of Mechanical and Manufacturing Engineering, Universiti Tun Hussein Onn \\ Malaysia, Batu Pahat, 86400 Johor, Malaysia \\ 2 Department of Food Science and Technology, Faculty of Applied Science, Rufus Giwa Polytechnic, Owo, Ondo State, Nigeria
}

\begin{tabular}{l} 
ARTICLE INFO ABSTRACT \\
\hline
\end{tabular}

\section{Article history:}

Received 27 July 2021

Received in revised form 23 October 2021

Accepted 25 October 2021

Available online 20 November 2021

\section{Keywords:}

Thermophysical properties; thermal degradation; enthalpy; biofluids; heat transfer fluid

\begin{abstract}
Thermal fluids modulate temperature conditions around the thermal collector systems indirectly by circulating the heat transfer fluid throughout the heat exchanger, thereby simulating cooling and heating with thermal condition. This study investigates biofluid from Moringa oleifera kernel, Date kernel, Palm kernel, Coconut kernel and Mango kernel as base fluids for heat transfer fluid application in solar thermal technology. The methodology employed in this study is experimental and the analyzed biofluids results was compared with conventional heat transfer base fluids. Thermal constant analyzer (TPS-2005S), CT-72 Transparent viscometer and Eagle eye SG-500 portable digital hydrometer were used to measure the thermophysical properties, viscosity, and density, of the biofluids respectfully. From the results, the biofluids showed comparative thermophysical properties to conventional base fluids. Moringa oleifera kernel oil and Mango kernel oil has the best quality among the biofluids with thermal conductivity, specific heat, viscosity, and density value was $0.1698 \mathrm{Wm} / \mathrm{k}, 1984.01 \mathrm{~J} / \mathrm{kg} . \mathrm{K}, 37.12 \mathrm{~mm}^{2} / \mathrm{s}$, $874.23 \mathrm{~kg} / \mathrm{m}^{3}$, and $0.2642 \mathrm{Wm} / \mathrm{k}, 763.18 \mathrm{~J} / \mathrm{kg} . \mathrm{K}, 45.27 \mathrm{~mm}^{2} / \mathrm{s}, 914.22 \mathrm{~kg} / \mathrm{m}^{3}$, respectively. The biofluids was thermally stable after exposure to several heating cycles and heating temperature as no significant degradation was observed in there thermophysical properties. However, there are needs for further experimental studies on clogging and possibility of enhancement of biofluids with organic nanoadditives.
\end{abstract}

\section{Introduction}

Energy consumption in building sector is on the rise, and the chunk of the energy consumed is for domestic water and space heating. For example, in residential and commercial buildings, process heat accounts for about $40 \%$ of the primary energy supply, at low and medium operating temperatures which can be achieved using solar thermal collectors [1,2]. In addition, thermal cleanings applied in food, pharmaceutical, automobile, textile industries, hospitals, and other healthcare sectors, heating operations range $\left(30^{\circ} \mathrm{C}\right.$ to $\left.120^{\circ} \mathrm{C}\right)$, can be achieved using flat-plate

\footnotetext{
* Corresponding author.

E-mail address: afoolabs@gmail.com; afoolabs@uthm.edu.my
}

https://doi.org/10.37934/arfmts.89.1.134141 
collectors, thus, reducing the reliance on conventional fossil fuels which is unclean and contributes to greenhouse gas emission $[3,4]$. Solar thermal collectors (STCS) systems are designed with buildings, as passive and active integrations, but the performance efficiency is very low and requires improvement. Several studies have proposed different enhancement techniques to STCs systems: thermal surface coating $[5,6]$, design configurations $[7,8]$, TES additives $[9,10]$, heat transfer fluid, $[11,12]$ and hybrid collector techniques, [13].

Heat transfer fluid (HTF) is major component of STCs because it's the medium of heat absorb and delivery. Water a conventional base fluid for nanofluids and hybrid nanofluids, in STCs system application, have been studied widely, $[14,15]$ but safety issues arising from the use of inorganic chemically synthesized base fluids and nanofluids use in food, drug and health related industries, as raised health concerns. Studies on biofluids for HTFs has attracted the interest of many researchers because of the green sustainable nature and the promising thermophysical and thermoelectric properties. In recent times, investigations on utilization of different types of biofluids as HTFs in food processing equipment's, medical and health related equipment's, macro and micro channels in electronics equipment's, heat exchanger equipment's, is gaining prominence among researchers focus. Base fluids like water, propylene glycol, ethylene glycol can cause corrosion and clogging in ducts and pipes sections, low thermal properties, freezing at low climatic condition and more importantly safety concerns because of nano-additives used for enhancement. These setbacks can be addressed by using fluid extracts from plant by-products of nonedible oils which a clean, sustainable, environmentally friendly, and comparative thermal properties with conventional base fluids. Still, less emphasis has been given on studies investigating biofluids as alternative heat transfer fluids. Therefore, this study, focuses on biofluids obtained from by-products of Moringa Oleifera (Moringaceae) kernel, Date (Phoenix dactylifera) kernel, Palm (Elaeis-guineensis) kernel, Coconut (Cocos nucifera) kernels and Mango (Mangifera indica) kernels for use as HTFs applications. Characterization of the biofluid thermophysical properties and thermal analysis was carried and compared with other conventional base fluids.

\section{Materials and Methods}

\subsection{List of Materials and Equipment}

Moringa Oleifera kernel oil (MOKO), Date kernel oil (DKO), Palm kernel oi (PKO), Coconut kernel oil (CKO), Mango kernel oil (MKO), measuring cylinder, conical flask, beaker, magnetic resonance stirrer, digital hot-plate, Thermal constant analyzer (TPS-2005S), CT-72 Transparent viscometer, Eagle eye SG-500 portable digital hydrometer, cold press machine, fridge, desiccator, METTLER TOLEDO benchtop portable digital density meter, thermometer, and stopwatch.

\subsection{Material Preparation}

$10 \mathrm{~kg}$ of Moringa oleifera kernel, Date kernel, Palm kernel, Coconut kernel and Mango kernels were purchased from local markets from Akure, Ondo state, Nigeria and from Ipoh, Perak, Malaysia. The seeds were sun-dried, picked to remove foreign materials, rotten and immature seeds and kept inside refrigerator until extraction.

\subsection{Cold Press Extraction Method}

A cold press machine model -SH-48-100, (Seng Hup Machine, Lahat Malaysia), of 100tons capacity, operated at $1350 \mathrm{psi}$, Stainless steel mold head circumference of $147.1 \mathrm{~mm}$ and thickness of 
$30.44 \mathrm{~mm}$. A 750g of biomass (MOKO, DKO, PKO, CKO and MKO) was placed inside muslin cloth and kept inside the hollow part of the mold and then subjected to pressing load of $100 \mathrm{~kg}$ at $45^{\circ} \mathrm{C}$ till oil recovery. The oil obtained was filtered, the amount of oil extracted was measured gravimetrically, and then centrifuge at 3500rpm for $20 \mathrm{mins}$, and kept in amber bottle, flush with Nitrogen gas and stored at $4^{\circ} \mathrm{C}$ till further. Figure 1 shows photo-image of the biomass seed, kernel, and the cold press machine.

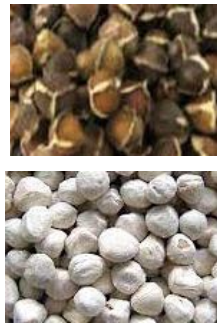

(a)

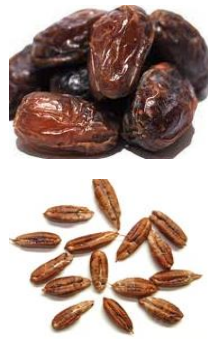

(b)

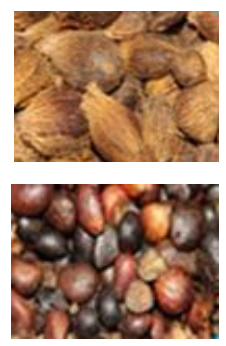

(c)

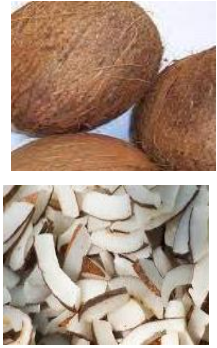

(d)

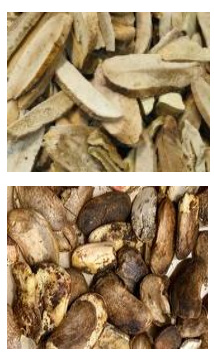

(e)

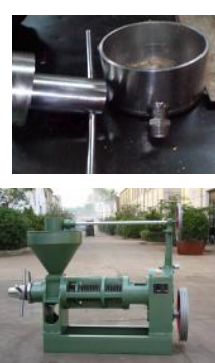

(f)

Fig. 1. (a) Moringa seed \& kernel (b) Date seed and kernel (c) Palm seed and kernel (d) Coconut seed and kernel (e) Mango seed and kernel (f) Cold press machines

\subsection{Characterization}

Thermophysical properties of the MOKO, DKO, PKO, CKO, and MKO was carried to determine the melting and boiling point, thermal conductivity, specific heat, thermal diffusivity, density, and viscosity. This are essential fluid properties that determines suitability for heat transfer fluids. Many reports $[16,17]$ on characterization of heat transfer fluids have been presented with fewer studies on biofluids [18]. $5 \mathrm{ml}$ for each of the biofluids samples was taken to the laboratory, the measurement was repeated in triplicates.

\subsection{Thermal Behavior}

Measurement of heating temperature and heating cycle was adopted as parameters of investigation. The heating temperature used was $120^{\circ} \mathrm{C}$, while 100 and 200 heating cycles was adopted was thermal degradation analysis. For each heating cycle, the oils are heated from ambient temperature to $120^{\circ} \mathrm{C}$, then allowed to cool till ambient temperature to complete one cycle. The process was repeated 100 and 200 heating cycle, with each taken 20 mins.

\section{Result and Discussion}

Result of biofluid characterization - The measured thermophysical properties of the biofluids is presented in Table 1. The melting and boiling temperature of the biofluids ranged from $(20(40))^{\circ} \mathrm{C}$ and $(160(310))^{\circ} \mathrm{C}$, this temperature is higher than the boiling temperature of water, propylene glycol, ethylene glycol and mixture of water / propylene glycol which implies can hold more heat and can be used at higher working temperatures. The MKO have the highest melting and boiling temperature among the biofluids. The biofluids can with stand $160^{\circ} \mathrm{C}$ without causing chemical changes, and thermally stable. 
Table 1

Thermophysical properties of biofluids oil

\begin{tabular}{lllllll}
\hline $\begin{array}{l}\text { Biofluid } \\
\text { Type }\end{array}$ & $\begin{array}{l}\text { Melting / Boiling } \\
\text { Point }^{\circ} \mathrm{C}\end{array}$ & $\begin{array}{l}\text { Thermal } \\
\text { Conductivity } \\
\lambda / \text { Wm-1k-1 } \\
30 \text { o C }\end{array}$ & $\begin{array}{l}\text { Specific } \\
\text { Heat } \\
\text { J/(kg.K) }\end{array}$ & $\begin{array}{l}\text { Thermal } \\
\text { Diffusivity } \\
\mathrm{m} 2 / \mathrm{s}\end{array}$ & $\begin{array}{l}\text { Viscosity } \\
(\mu) \\
\mathrm{mm} 2 / \mathrm{s}\end{array}$ & $\begin{array}{l}\text { Density } \\
(\rho) \\
\mathrm{Kg} / \mathrm{m} 3\end{array}$ \\
\hline MOKO & $21 / 186$ & 0.1698 & 1984.01 & 0.00061 & 37.12 & 874.23 \\
DKO & $37 / 165$ & 0.1384 & 1642.53 & 0.00076 & 29.65 & 711.24 \\
PKO & $26 / 218$ & 0.1421 & 1773.24 & 0.00054 & 32.33 & 928.11 \\
CKO & $25 / 260$ & 0.1659 & 2401.23 & 0.00016 & 3.24 & 919.04 \\
MKO & $39 / 305$ & 0.2642 & 2763.18 & 0.00023 & 45.27 & 914.22 \\
\hline
\end{tabular}

Thermal conductivity of the HTF is an important thermophysical property which influences the Nusselt number and sensitive to temperature. Higher thermal conductivity means faster rate of heat transfer between the constituents. From the measured biofluid thermal conductivity data, the MKO had the highest values with $0.264 \mathrm{Wm} / \mathrm{K}$, and lowest was DKO with $0.1384 \mathrm{Wm} / \mathrm{K}$. Other values are $0.1698,0.1659$ and $0.142 \mathrm{Wm} / \mathrm{K}$, for MOKO, CKO and PKO, respectively. This values are comparable to conventional base fluids, and suitable for HTFs in thermal applications because higher thermal conductivity implies good heat transfer mechanism within the fluid $[3,11]$. Synthetic thermal oil when heated above operating temperature decomposes quickly, producing hydrogen gas, degrades and reduce the life cycle and thermal efficacy. Water is utilized as the conventional HTFs in STC system because of its appreciable heat capacity of $4.185 \mathrm{~J} / \mathrm{Kg} \mathrm{K}$. Although, from this study, the biofluids had lower specific heat values compared to water but higher than mixture of water/propylene glycol. The specific heat of MKO was the highest $2.764 \mathrm{~J} / \mathrm{Kg} . \mathrm{K}$, while the MOKO, DKO, PKO, and CKO values are $1984.01,1642.03,1773.24$, and $2401 \mathrm{~J} / \mathrm{Kg} . \mathrm{K}$, respectively. Viscosity is a measure of an oil's resistance to flow, lower viscosity enhances fluid flows, reduce heat dissipation caused by friction, the measured viscosities of CKO $(3.24 \mathrm{~mm} 2 / \mathrm{s})$ was the lowest and closer to water, $[19,20]$. The remaining biofluids exhibited higher viscosities with average of $35.03 \mathrm{~mm} 2 / \mathrm{s}$, which within range of commonly used base fluid mixtures. The biofluids viscosity reduces as the temperature increases and cause lower oil consumption and less wear during fluid flow. Overall, the oil viscosity values are suitable for heat transfer fluid in thermal applications. The transfer of momentum and heat is affected by variable density, because convective heat transfer is affected by density differential within fluid flow, [21]. The density values of the biofluids are 874.23, 711.24, 928.11, 919.04 and 914.22, $(\mathrm{Kg} / \mathrm{m} 3)$, for MOKO, DKO, PKO, CKO and MKO, respectively. The biofluid densities are comparatively better than water, water/propylene mixture, water/ethylene mixture and some nanofluids. This density values decrease as oil temperature increases and will become less dense in presence of heat. Thermal behavior of the biofluids is shown in Table 2 .

Table 2

Melting and crystallization behavior of bio-oil

\begin{tabular}{lllllllll}
\hline \multicolumn{3}{c}{ Melting Temperature $\left({ }^{\circ} \mathrm{C}\right)$} & \multicolumn{4}{c}{ Crystallization Temperature $\left({ }^{\circ} \mathrm{C}\right)$} \\
& Onset & Peak & End & Onset & Peak 1 & Peak 2 & End \\
\hline MKO & -15.86 & -3.82 & 3.21 & 5.92 & 4.60 & -39.87 & 2.67 \\
DKO & -13.83 & -4.92 & 0.55 & 7.32 & 5.91 & -43.75 & 3.17 \\
PKO & -14.34 & -3.19 & 2.02 & 5.87 & 3.93 & -41.06 & 1.25 \\
CKO & -13.12 & -4.90 & 0.55 & 7.32 & 5.91 & -43.75 & 3.17 \\
MKO & -14.34 & -3.19 & 2.02 & 5.87 & 3.93 & -41.06 & 1.25 \\
\hline
\end{tabular}


The resulting DSC data was analyzed with respect to their melting temperature (Tm), crystallization temperature (Tc), endset temperature (Test) and enthalpy. Melting temperature was considered as the temperature at which a material change from solid to liquid [22], while the end temperature is the complete melting temperature of triglyceride. The melting behavior reveal onset point started from -13.12 and $-15.86^{\circ} \mathrm{C}$ for all the biofluids. The oils exhibited close peak temperature during melting with the highest peak reached at $-4.92^{\circ} \mathrm{C}$ for $\mathrm{DKO}$ and $-4.90^{\circ} \mathrm{C}$ for $\mathrm{CKO}$. During crystallization, the average onset and endset temperature was 4.05 and $2.25^{\circ} \mathrm{C}$, respectively. The MOKO shows a broadening peak, and tends towards higher temperature, compared to DKO, PKO, CKO and MKO. This result indicate that melting behavior depends on the physicochemical and thermal properties of the oils. Samaram, Mirhosseini [23], reported similar findings that melting behavior of oil depends on their extraction process parameters. The amount of heat released or absorbed during a chemical reaction carried out at constant pressure is the enthalpy, [24]. Table 3 shows the internal energy of the biofluids. From the result, the MKO and MOKO had the highest enthalpies at $64.23 \pm 0.2$ and $59.46 \pm 0.5$, which implies their suitability for heat transfer fluid compared to some conventional base fluids. However, the MOKO had larger transition period $(-3.82 \pm 0.1$ to $39.87 \pm 0.3)$, from melting to crystallization compared to the rest of the biofluids. The biofluid enthalpy is increased as the fluid temperature increases, thus improve convective heat transfer between the fluid and heat exchanger systems.

Table 3

Enthalpy of biofluids oils

\begin{tabular}{|c|c|c|c|c|}
\hline $\begin{array}{l}\text { Extraction } \\
\text { Method }\end{array}$ & $\begin{array}{l}\text { Enthalpy } \\
\Delta \mathrm{H}(\mathrm{Kj} / \mathrm{Kg})\end{array}$ & $\begin{array}{l}\text { Glass Transition } \\
T_{G}(\stackrel{o}{C})\end{array}$ & $\begin{array}{l}\text { Melting Temperature } \\
T_{m}(\stackrel{o}{C})\end{array}$ & Crystallization Temperature $T_{c}(\stackrel{o}{ } C)$ \\
\hline MOKO & $59.46 \pm 0.5$ & $43.79 \pm 0.1$ & $-3.82 \pm 0.1$ & $-39.87 \pm 0.3$ \\
\hline DKO & $48.30 \pm 0.4$ & $40.63 \pm 0.3$ & $-4.92 \pm 0.2$ & $-43.75 \pm 0.2$ \\
\hline PKO & $52.14 \pm 0.3$ & $39.08 \pm 0.2$ & $-3.19 \pm 0.1$ & $-41.06 \pm 0.5$ \\
\hline CKO & $41.26 \pm 0.1$ & $37.15 \pm 0.2$ & $-3.44 \pm 0.3$ & $-38.19 \pm 0.2$ \\
\hline MKO & $64.23 \pm 0.2$ & $46.37 \pm 0.3$ & $-5.28 \pm 0.1$ & $-45.42 \pm 0.3$ \\
\hline
\end{tabular}

Thermal analysis was carried out on the biofluid oils to determine thermal reliability after several heating temperature and heating cycles. Table 4 shows the thermal reliability parameters for the oils. Each of the oil was subjected to 100 and 200 heating cycles at constant heating temperature $\left(120^{\circ} \mathrm{C}\right)$. From the result, the thermal conductivity values of the biofluids reduced by $7.2 \%: 14.3 \%$ (MOKO), 6.6\%:13.6\% (DKO), 1.9\%:4.9\% (PKO), 1.9\%:2.9\% (CKO), 2.7\%:3.1\% (MKO) for 100 and 200 heating cycles, respectively.

It is observed that the heating cycle impacted the oil thermophysical properties because of gradual degradation in the oil physicochemical properties. The impact was higher on the 200-heating cycle for all the biofluids thermal conductivity, with MOKO and DKO having the highest degradation with $14.3 \%$ and $13.6 \%$, respectively. Whereas the heating cycle impacted less on the PKO (1.9\%) and CKO (2.7\%), thermal conductivity after 200-heating cycles. Thermal conductivity are temperature dependents and oils are temperature sensitive, most reports agreed that heating degrades thermal properties, [19].

The specific heat degradation effects on heating cycle and temperature of the biofluids showed degradation of 3.1\%:8.5\% (MOKO), 7.9\%:11.7\% (DKO), 8.2\%:10.1\% (PKO), 0.7\%:1.8\% (CKO), 1.9\%:2.1\% (MKO) for 100 and 200 heating cycles, respectively. The CKO (1.8\%), and MKO (2.1\%), had less degradation changes compared with the MOKO (8.5\%), DKO (11.7\%) and PKO (10.1\%). The viscosity degradation effects on heating cycle and temperature of the biofluids showed degradation of 3.9\%:12.7\% (MOKO), 3.3\%:17.2\% (DKO), 13.8\%:23.8\% (PKO), 1.9\%:43.2\% (CKO), 6.2\%:8.5\% (MKO) 
for 100 and 200 heating cycles, respectively. The PKO (23.8\%), and CKO (43.2\%), had higher degradation effects compared with the MOKO (12.7\%), DKO (17.2\%) and MKO (6.5\%). Thus, as heating cycle increases, the viscosity degrades especially for the PKO which will impact the biofluid flow in thermal applications. The density degradation effects on heating cycle and temperature of the biofluids showed degradation of 3.7\%:10.6\% (MOKO), 4.1\%:4.2\% (DKO), 3.1\%:6.2\% (PKO), 0.9\%:2.1\% (CKO), 0.8\%:1.2\% (MKO) for 100 and 200 heating cycles, respectively. The MOKO (10.6\%), and PKO (6.2\%), had higher degradation density effects compared with the DKO (4.2\%), CKO (1.2\%) and MKO (1.2\%). As the heating cycle increases, the density values degrade especially for the MOKO which made it denser compared to the initial values $[25,26]$. Summarily, the biofluids properties are thermally stable, low viscosity, high enthalpy, large glass transition, and low operating temperature. This property makes this biofluids suitable for thermal transports in heat transfer application.

Table 4

Thermal analysis of biofluids and conventional fluids

\begin{tabular}{|c|c|c|c|c|c|c|c|c|c|c|}
\hline \multicolumn{11}{|c|}{ Heat Transfer Fluids } \\
\hline $\begin{array}{l}\text { Biofluid } \\
\text { Types }\end{array}$ & MOKO & & DKO & & PKO & & CKO & & MKO & \\
\hline $\begin{array}{l}\text { Thermal } \\
\text { Parameters }\end{array}$ & $\begin{array}{l}100 \\
\text { heating } \\
\text { cycle at } \\
\text { heating } \\
\text { temp } \\
120^{\circ} \mathrm{C}\end{array}$ & $\begin{array}{l}200 \\
\text { heating } \\
\text { cycle at } \\
\text { heating } \\
\text { temp } \\
120^{\circ} \mathrm{C}\end{array}$ & $\begin{array}{l}100 \\
\text { heating } \\
\text { cycle at } \\
\text { heating } \\
\text { temp } \\
120^{\circ} \mathrm{C}\end{array}$ & $\begin{array}{l}200 \\
\text { heating } \\
\text { cycle at } \\
\text { heating } \\
\text { temp } \\
120^{\circ} \mathrm{C}\end{array}$ & $\begin{array}{l}100 \\
\text { heating } \\
\text { cycle at } \\
\text { heating } \\
\text { temp } \\
120^{\circ} \mathrm{C}\end{array}$ & $\begin{array}{l}200 \\
\text { heating } \\
\text { cycle at } \\
\text { heating } \\
\text { temp } \\
120^{\circ} \mathrm{C}\end{array}$ & $\begin{array}{l}100 \\
\text { heating } \\
\text { cycle at } \\
\text { heating } \\
\text { temp } \\
120^{\circ} \mathrm{C}\end{array}$ & $\begin{array}{l}200 \\
\text { heating } \\
\text { cycle at } \\
\text { heating } \\
\text { temp } \\
120^{\circ} \mathrm{C}\end{array}$ & $\begin{array}{l}100 \\
\text { heating } \\
\text { cycle at } \\
\text { heating } \\
\text { temp } \\
120^{\circ} \mathrm{C}\end{array}$ & $\begin{array}{l}200 \\
\text { heating } \\
\text { cycle at } \\
\text { heating } \\
\text { temp } \\
120^{\circ} \mathrm{C}\end{array}$ \\
\hline \multicolumn{11}{|c|}{ Thermophysical Reliability } \\
\hline \multicolumn{11}{|c|}{ Thermal } \\
\hline \multicolumn{11}{|l|}{$\begin{array}{l}\mathrm{y} \\
\lambda / \mathrm{Wm}^{-1} \mathrm{k}^{-1}\end{array}$} \\
\hline Heat & 1864.0 & 1672.2 & 1401.3 & 1274.1 & 1504.2 & 1448.6 & 2364.0 & 2316.1 & 2661.2 & 2652.4 \\
\hline $\mathrm{J} /(\mathrm{kg} . \mathrm{K})$ & 3 & 8 & 4 & 4 & 8 & 2 & 4 & 3 & 7 & 1 \\
\hline \multicolumn{11}{|l|}{ Thermal } \\
\hline Diffusivity & 0.0005 & 0.0004 & 0.0006 & 0.0006 & 0.0004 & 0.0003 & 0.0001 & 0.0001 & 0.0002 & 0.0002 \\
\hline$\left[\times 10^{-6} \mathrm{~m}^{2} / \mathrm{s}\right]$ & 3 & 2 & 8 & 2 & 2 & 8 & 6 & 6 & 3 & 3 \\
\hline \multicolumn{11}{|l|}{ Viscosity $(\mu)$} \\
\hline & 2 & 2 & 1 & 5 & 4 & 2 & & & & \\
\hline \multicolumn{11}{|l|}{ Density $(\rho)$} \\
\hline $\mathrm{Kg} / \mathrm{m}^{3}$ & 842.43 & 786.24 & 683.21 & 640.14 & 900.16 & 872.33 & 927.22 & 938.04 & 921.22 & 925.32 \\
\hline Melting / & 19.4 & 18.2 & 35.5 & 34.7 & 25.3 & 24.2 & 26.4 & 27.2 & 40.2 & 41.4 \\
\hline Boiling & / & / & / & / & / & / & / & / & / & / \\
\hline Temp $\left({ }^{\circ} \mathrm{C}\right)$ & 179 & 178 & 163 & 162 & 222 & 220 & 263 & 264 & 301 & 299 \\
\hline
\end{tabular}

\section{Conclusion}

Summarily, it is estimated that about $35 \%$ of the process heat demand could be covered with low to medium temperature solar collector systems. One key component of STC enhancement is the HTFs. Conventional base fluids like water and mixture of water/propylene glycol have been enhanced using nano additives. However, the setbacks of corrosion, clogging, freezing, and toxicity persist. The use of biofluid as alternative base fluid can address some of the setbacks in conventional base fluid 
and base fluid mixtures. In this study, the characterized biofluids demonstrated quality properties suitable for HTF application and comparable to conventional base fluids used in various thermal technologies. Among the biofluids, the MKO and MOKO showed optimal quality compare to the other fluids. No significant degradation was observed in the quality properties of the biofluids after undergoing several heating temperature and heating cycle. However, further investigation is recommended on thermal stability of the oils after extended cycles. In addition, synthesizing the biofluids with organic nano additives can improve the oil thermophysical properties. Experimental investigation utilizing biofluids as HTFs in various solar thermal technology, micro and macro channel heat exchangers is recommended to confirm the thermal enhancement and system performance.

\section{Declaration of Competing Interest}

The author(s) declared no potential conflicts of interest with respect to the research, authorship, and/or publication of this article.

\section{Acknowledgements}

The corresponding author acknowledge the Research Management Centre, (RMC), Universiti Tun Hussein Onn Malaysia for the financial support under the RMC TIER-1 (H829) and RMC Research Fund (E15501).

\section{References}

[1] Afolabi, Lukmon Owolabi, Zulkifli Mohamad Ariff, Puteri Sri Melor Megat-Yusoff, Hussain H. Al-Kayiem, Adiat Ibironke Arogundade, and Oluwafunke T. Afolabi-Owolabi. "Red-mud geopolymer composite encapsulated phase change material for thermal comfort in built-sector." Solar Energy 181 (2019): $464-474$. https://doi.org/10.1016/i.solener.2019.02.029

[2] Khattak, Muhammad Adil, Mohammad Azfar Haziq Ayoub, Muhammad Ariff Fadhlillah Abdul Manaf, Mohd Faidhi Mahru, Mohd Ridwan Mohd Juhari, Mira Idora Mustaffa, and Suhail Kazi. "Global energy security and European Union: A review." Journal of Advanced Research in Applied Sciences and Engineering Technology 11, no. 1 (2018): 64-81.

[3] Afolabi, Lukmon Owolabi, Hussain Hamoud Al-Kayiem, and Tesfamichael Baheta Aklilu. "Performance analysis of integrated collector system with immersed coil heat exchanger." In Applied Mechanics and Materials, vol. 660, pp. 740-744. Trans Tech Publications Ltd, 2014. https://doi.org/10.4028/www.scientific.net/AMM.660.740

[4] Verma, Sujit Kumar, Kamal Sharma, Naveen Kumar Gupta, Pawan Soni, and Neeraj Upadhyay. "Performance comparison of innovative spiral shaped solar collector design with conventional flat plate solar collector." Energy 194 (2020): 116853. https://doi.org/10.1016/j.energy.2019.116853

[5] Thappa, Sahil, Aditya Chauhan, A. Sawhney, Y. Anand, and S. Anand. "Thermal selective coatings and its enhancement characteristics for efficient power generation through parabolic trough collector (PTC)." Clean Technologies and Environmental Policy 22, no. 3 (2020): 557-577. https://doi.org/10.1007/s10098-020-01820-3

[6] Al-Kayiem, Hussain H., Saw C. Lin, and Afolabi Lukmon. "Review on nanomaterials for thermal energy storage technologies." Nanoscience \& Nanotechnology-Asia 3, no. $\quad 1 \quad$ (2013): https://doi.org/10.2174/22113525113119990011

[7] Rejeb, Oussama, Leon Gaillard, Stéphanie Giroux-Julien, Chaouki Ghenai, Abdelmajid Jemni, Maamar Bettayeb, and Christophe Menezo. "Novel solar PV/Thermal collector design for the enhancement of thermal and electrical performances." Renewable energy 146 (2020): 610-627. https://doi.org/10.1016/i.renene.2019.06.158

[8] Cao, Yan, Abdeliazim Mustafa Mohamed, Mahidzal Dahari, Mostafa Delpisheh, and Maghsoud Abdollahi Haghghi. "Performance enhancement and multi-objective optimization of a solar-driven setup with storage process using an innovative modification." Journal of Energy Storage $32 \quad 101956$. https://doi.org/10.1016/j.est.2020.101956

[9] Huang, Haotian, Yimin Xiao, Jianquan Lin, Tiecheng Zhou, Yanan Liu, and Qian Zhao. "Improvement of the efficiency of solar thermal energy storage systems by cascading a PCM unit with a water tank. "Journal of Cleaner Production 245 (2020): 118864. https://doi.org/10.1016/i.jclepro.2019.118864

[10] Kalidasan, B., A. K. Pandey, Syed Shahabuddin, M. Samykano, M. Thirugnanasambandam, and R. Saidur. "Phase change materials integrated solar thermal energy systems: Global trends and current practices in experimental approaches." Journal of Energy Storage 27 (2020): 101118. https://doi.org/10.1016/i.est.2019.101118 
[11] Krishna, Yathin, M. Faizal, R. Saidur, K. C. Ng, and Navid Aslfattahi. "State-of-the-art heat transfer fluids for parabolic trough collector." International Journal of Heat and Mass Transfer 152 (2020): 119541. https://doi.org/10.1016/j.ijheatmasstransfer.2020.119541

[12] Owolabi, Afolabi L., Hussain H. Al-Kayiem, and Aklilu T. Baheta. "Performance investigation on a thermal energy storage integrated solar collector system using nanofluid." International Journal of Energy Research 41, no. 5 (2017): 650-657. https://doi.org/10.1002/er.3657

[13] Li, Xiaoke, Guangyong Zeng, and Xinyu Lei. "The stability, optical properties and solar-thermal conversion performance of SiC-MWCNTs hybrid nanofluids for the direct absorption solar collector (DASC) application." Solar Energy Materials and Solar Cells 206 (2020): 110323. https://doi.org/10.1016/i.solmat.2019.110323

[14] Rafiq, Muhammad, Muhammad Shafique, Anam Azam, and Muhammad Ateeq. "Transformer oil-based nanofluid: The application of nanomaterials on thermal, electrical and physicochemical properties of liquid insulation-A review." Ain Shams Engineering Journal 12, no. 1 (2021): 555-576. https://doi.org/10.1016/i.asej.2020.08.010

[15] Ansarpour, Meisam, Elnaz Danesh, and Masoud Mofarahi. "Investigation the effect of various factors in a convective heat transfer performance by ionic liquid, ethylene glycol, and water as the base fluids for Al2O3 nanofluid in a horizontal tube: A numerical study." International Communications in Heat and Mass Transfer 113 (2020): 104556. https://doi.org/10.1016/i.icheatmasstransfer.2020.104556

[16] Rajendran, Duraisamy Ramalingam, Esakkimuthu Ganapathy Sundaram, Paulraj Jawahar, Vaithilingam Sivakumar, Omid Mahian, and Evangelos Bellos. "Review on influencing parameters in the performance of concentrated solar power collector based on materials, heat transfer fluids and design." Journal of Thermal Analysis and Calorimetry 140, no. 1 (2020): 33-51. https://doi.org/10.1007/s10973-019-08759-8

[17] Guo, Zhixiong. "A review on heat transfer enhancement with nanofluids." Journal of Enhanced Heat Transfer 27, no. 1 (2020). https://doi.org/10.1615/JEnhHeatTransf.2019031575

[18] Salman, S., AR Abu Talib, S. Saadon, and MT Hameed Sultan. "Hybrid nanofluid flow and heat transfer over backward and forward steps: A review." Powder Technology 363 (2020): $448-472$. https://doi.org/10.1016/j.powtec.2019.12.038

[19] Hosseinghorbani, Armin, Mehrdad Mozaffarian, and Gholamreza Pazuki. "Application of graphene oxide IoNanofluid as a superior heat transfer fluid in concentrated solar power plants." International Communications in Heat and Mass Transfer 111 (2020): 104450. https://doi.org/10.1016/i.icheatmasstransfer.2019.104450

[20] Ahmad, Salman, Habib Ullah, T. Hayat, and A. Alsaedi. "Computational analysis of time-dependent viscous fluid flow and heat transfer." International Journal of Modern Physics B 34, no. 13 (2020): 2050141. https://doi.org/10.1142/S0217979220501416

[21] Tetuko, Anggito P., Lukman F. Nurdiyansah, Muhammad Addin, Eko A. Setiadi, Masno Ginting, and Perdamean Sebayang. "Magnetic nanofluids as heat transfer media in heat pipes." Advances in Natural Sciences: Nanoscience and Nanotechnology 11, no. 2 (2020): 025002. https://doi.org/10.1088/2043-6254/ab878e

[22] Puangsri, T., S. M. Abdulkarim, and H. M. Ghazali. "Properties of Carica papaya L.(papaya) seed oil following extractions using solvent and aqueous enzymatic methods." Journal of Food Lipids 12, no. 1 (2005): 62-76. https://doi.org/10.1111/i.1745-4522.2005.00006.x

[23] Samaram, Shadi, Hamed Mirhosseini, Chin Ping Tan, Hasanah Mohd Ghazali, Sara Bordbar, and Alireza Serjouie. "Optimisation of ultrasound-assisted extraction of oil from papaya seed by response surface methodology: Oil recovery, radical scavenging antioxidant activity, and oxidation stability." Food Chemistry 172 (2015): 7-17. https://doi.org/10.1016/j.foodchem.2014.08.068

[24] Jung, Christian, Anke Nietsch, and Carsten Spenke. "Determination of isobaric enthalpy differences of heat transfer fluids." In AIP Conference Proceedings, vol. 2303, no. 1, p. 100004. AIP Publishing LLC, 2020. https://doi.org/10.1063/5.0028892

[25] Gaedtke, Maximilian, S. Abishek, Ryan Mead-Hunter, Andrew JC King, Benjamin J. Mullins, Hermann Nirschl, and Mathias J. Krause. "Total enthalpy-based lattice Boltzmann simulations of melting in paraffin/metal foam composite phase change materials." International Journal of Heat and Mass Transfer 155 (2020): 119870. https://doi.org/10.1016/j.ijheatmasstransfer.2020.119870

[26] Idris, Muhammad Syafiq, Irnie Azlin Zakaria, and Wan Azmi Wan Hamzah. "Heat Transfer and Pressure Drop of Water Based Hybrid Al2O3: SiO2 Nanofluids in Cooling Plate of PEMFC." Journal of Advanced Research in Numerical Heat Transfer 4, no. 1 (2021): 1-13. 